\title{
Analysis of Dismounted Operation Support with Robots
}

\author{
Marian Janusz LOPATKA ${ }^{1}$, Tomasz MUSZYŃSKI ${ }^{2}$
}

\author{
Military University of Technology, Institute of Mechanical Engineering, 2 gen. Witolda \\ Urbanowicza Street, 00-908, Poland ${ }^{1}$ \\ E-mails: ${ }^{1}$ marian.lopatka@wat.edu.pl; ${ }^{2}$ tomasz.muszynski@wat.edu.pl
}

\begin{abstract}
Military operation in rough terrain are very often conducted as dismounted operation. In this condition the logistic support is very problematic because all equipment is carried by soldier. It reduces the mobility and agility of troops.

In the paper the demand for supporting dismounted operation UGV are described and concept of robot's solutions are presented.
\end{abstract}

KEY WORDS: mobile robot, Unmanned Ground Vehicle, UGV, logistic support, dismounted operation.

\section{Introduction}

Increasing combat abilities and the range of tasks performer by certain subdivisions results in an upsurge in both the weight of armaments and equipment that they must transport with them. That problem is particularly prominent in groups performing their tasks on foot. It's currently estimated that a 3-day expedition requires each soldier to carry up to $75 \mathrm{~kg}$ of equipment, while a single day military patrol indicates a burden of up to $45 \mathrm{~kg}$. Single-handed carrying of such weights decidedly decreases the mobility of soldiers, thus prolonging the time needed to complete a task and lessening the probability of success. It also creates a considerable hazard in terms of battlefield survival.

In order to improve the situation, the carried weight would have to be limited to $25 \mathrm{~kg}$ per soldier - including standard armament, ammunition, uniforms, bulletproof vests, a helmet and personal means of connections. Other equipment necessary for fulfilling the task should be shipped via separate means of transport, moving directly with a team or a platoon, as indicated by military experience of British and American armies in Afghanistan. The forces used crossing quads with trailers (carrying capacity of 300-400 kg). That solution improved both the mobility and the combat quality of pedestrian subdivisions, but it was not devoid of shortcomings. When crossing a rough terrain, the speed of marching falls to 1-3 $\mathrm{km} / \mathrm{h}$ and since the quads' powertrains were neither adjusted to such slow speeds, nor used to overcoming certain hurdles, problems arose. It is also worth mentioning that the number of soldiers ready for interventions was decreased, as drivers were forced to focus solely on steering the quads. In addition, they have too low off-road mobility.

It can be concluded that in order to support the soldiers directly on the battlefield, one should use UGVs (robots) capable of following a guide - a selected soldier. They should navigate around obstacles autonomically and exhibit mobility close to that of an infantry soldier. Unmanned vehicles (platforms) are expected to transport the necessary supplies of ammunition, warfare, team weapons, food and water, communications, backup power supplies, camping gear, etc. If necessary, they will also serve as means to evacuate the wounded. Transportation at an operational level does not place vehicles on such high demands in terms of off-road properties. The available communication routes are used, which in most cases allow the use of standard trucks. A separate issue is that there must be a significantly higher efficiency of such a system. To ensure these vehicles with a load capacity of a dozen or so on even tens of tons should be used. By using the results of one of the research programs, commissioned by the US Army, it can be concluded that the implementation of robots of logistic support at the operational level is currently pointless. As part of it, trucks were robotized and adapted to autonomous movement in the marching column. Despite the positive results of the work, it was not decided to apply this solution in practice. It was dictated, among others experience gained by the American army from the activities carried out in recent years in Iraq and Afghanistan. As part of it, trucks were robotized and adapted to autonomous movement in the marching column. Despite the positive results of the work, it was not decided to apply this solution in practice.

In addition to tests under normal road conditions, where the system worked properly, simulated its behavior in the fire action of the opponent (such as the explosion of the trap mines) and tested the resistance to takeover by the opponent. They showed that in such a case there may be a serious increase in the risk of internal forces, which negatively affect the safety of operations and the size of losses. To avoid this, it is therefore necessary to provide a high degree of protection for the march of unmanned vehicles. In the opinion of project commissioners, the balance of advantages and disadvantages, in connection with the total costs of implementing and using the system, turned out to be unfavorable.

Bearing in mind the above conditions, it can be concluded that the most desirable logistic support platforms will be solutions based on the tactical level, i.e. the team, team and troop.

The analysis of operations conducted as part of contemporary armed conflicts allows us to conclude that at least two sizes of robots for logistic support are desirable: 
a) light - with a load capacity of $200 \div 400 \mathrm{~kg}$ and own weight of $500 \div 800 \mathrm{~kg}$,

b) heavy - with a load capacity of about $2,000-3,000 \mathrm{~kg}$ and own weight of 4,000 $\div 5,000 \mathrm{~kg}$.

The smaller one would be intended to support team or team level activities. The weight of the transported cargo is sufficient to carry $30 \div 40 \mathrm{~kg}$ of individual and team equipment for each team soldier.

The heavy platform would have to support team or platoon activities. It would be possible to provide supplies for sub-units (ammunition, weapons, food, water, dams, etc.) directly to the places of their dislocation, where often there are no roads that could be used by off-road vehicles. In the area of applications, it would also be possible to transfer the equipment of the whole troop, moving in a pedestrian formation into a new place of task implementation. A desirable feature of the case of this platform is to make it easy to take and transport palletized loads

\section{Investigation Results}

The tactics of logistic support robots' usage will depend on the nature of tasks performed by each subdivision. There are three main scenarios of their usage that can be predicted.

The elementary scenario consists of transporting the equipment of subdivisions on platoon level, a team, a group or a single soldier operating on foot on a rough terrain, where using standard SUVs proves to be difficult, impossible or futile. The robots will then move within or behind the grouping, using the option of remote control by the operator or follow the soldier-guide independently. In addition to the transfer of the equipment itself, it is also possible to use such platforms as a means of transport for soldiers. Control should then take place using the on-board system

Another form of usage will be an autonomically transport of equipment between given points, allowing for complementing soldiers' provisions or providing additional tools. The platform should then move in a coordinated way. This type of activity will be able to be implemented in areas and at distances that minimize the risk of taking over the robot by the opponent or making it his own combat agent, as well as in areas This type of activity will be able to be implemented in areas and at distances that minimize the risk of taking over the robot by the opponent or making it his own combat agent, as well as in areas threatened by its fire action.

The third nature of platform's actions will be tied to evacuating wounded soldiers from areas unsuitable for first-aid. Such a task would be carried out by a robot $\mathrm{i}$ if it would be dangerous for life or health to be carried out by humans. The robot control would then take place in the teleoperation mode. It is also expected that platforms with adequate payload $(\min 80 \mathrm{~kg})$ and the size of the cargo space will be able to be used to transport wounded unable to move on their own - to medical help points. This task should be carried out autonomously.

An additional function of the logistic support robots would be to use them as a power source, mainly electric, for other devices and systems (radio stations, listening stations, interfering stations, etc.).

It is also acceptable to use them for simple image recognition, based on standard on-board cameras. This would take place when the development of the combat situation would make it impossible to use (owning, reaching or bringing back) dedicated applications for this purpose.

A very important feature of these platforms is mobility in the broad sense. Its basic indicators will be speed, ability to overcome obstacles and maneuverability. No less important is also the time of continuous work, i.e. without refueling or power sources. It should be enough for at least one day mission, both day and night. In military conditions, it cannot be less than 10 hours, $80 \%$ of this time should be for driving at a speed of $5 \mathrm{~km} / \mathrm{h}$. It is desirable, however, that it is possible to carry out missions lasting $24 \div 72 \mathrm{~h}$.

Logistic support robots should be equipped with a control system ensuring them to perform tasks in the following modes:

- following a designated soldier-guide (so-called "follow me" function) with autonomous detection and bypassing obstacles (including mobile ones);

- remote control with the controller (range at least $100 \mathrm{~m}$ in urban areas and at least $500 \mathrm{~m}$ in open areas) with the desired teleoperation option;

- autonomous navigation around the designated route;

- on-board control (an operator driving on a robot or walking close to it).

It is also desirable to consider the possibility of issuing selected commands by a voice or gesture.

The maximum speed should be at least $13-15 \mathrm{~km} / \mathrm{h}$, which is equal to that obtained by a soldier running with armament. It is advisable to develop up to $30 \mathrm{~km} / \mathrm{h}$, which in turn results from the maximum speed achieved by the average person. Efforts should be made to minimize robot signatures, ensure protection of transported equipment and protect against unauthorized use.The option available for these carriers should also be to equip them with a system allowing the evacuation of the wounded. In the basic scope, it should be understood as taking them from the area endangered by the enemy's fire action. It is permissible to do this by grasping the victim for the uniforms (equipment), limb or stretcher and pulling after the robot. It is desirable that this task could be carried out in the mode of teleoperation. In the extended form of the evacuation function, one should additionally ensure the possibility of wounded transport on the / to the place where specialized assistance was provided.

In order to meet these expectations at the Military University of Technology, work was undertaken to create a base chassis for a light logistic class platform. By entering the design works, it was assumed that its total weight should be about $800 \mathrm{~kg}$, and mobility should correspond to the possibilities of a man moving with 30-40 kg load. In terms of terrain properties, it was assumed that the robot should be able to, inter alia:

- overcome high curbs; 
- drive up the standard stairs;

- move around the rubble;

- move in the desert area;

- overcome the narrows with a width of approx. $1.2 \div 1.5 \mathrm{~m}$ (narrow streets, forest and mountain paths, etc.).

In turn with reference to maneuverability, the turning radius should definitely be smaller than that obtained by light off-road vehicles, below approx. $4 \mathrm{~m}$. It is even desirable to make a return in place. The logistic platform designed for direct and comprehensive logistic support of pedestrian sub-units operating in very rough terrain, which eliminates the possibility of support by standard vehicles, must be able to overcome difficult terrain and develop the speed of travel, adapted human capabilities. Difficult terrain should be understood as both the type of the ground and its sculpture, obstacles and vegetation growing on it. The ability to overcome should be considered in conjunction with the expected speed and secrecy of moving sub units. These speeds largely depend on the type of tasks being carried out:

- during the walk, in favorable terrain conditions usually take the form of $3-5 \mathrm{~km} / \mathrm{h}$;

- if necessary, fast regrouping can reach $7-8 \mathrm{~km} / \mathrm{h}$ (fast march), and even $12-15 \mathrm{~km} / \mathrm{h}$ (gear with equipment and weapons);

- during patrol in the area with high threat of advancing speed they drop below $3 \mathrm{~km} / \mathrm{h}$ (up to $1 \mathrm{~km} / \mathrm{h}$ ).

Such low speeds cause problems for standard vehicles because their traction characteristics are adapted to higher travel speeds. In addition, there are problems with overcoming obstacles due to the low speed and inability to use the inertia of the vehicle.

The main advantage of the platform should be the ability to overcome terrain obstacles not available especially for standard military wheeled vehicles, at a speed adapted to moving supported sub-units. They include:

- areas with low bearing capacity, in particular crop areas, after rainfall or during thaw;

- stony areas (boulders);

- dune areas (sandy);

- areas covered with vegetation with available narrow forest paths;

- wilderness with large inequalities;

- roadside and drainage ditches.

According to the assumptions, the main purpose of the platform is to transport loads weighing $250 \mathrm{~kg}$, which may include: team weapons, team and personal weapon ammunition, personal soldiers' equipment, means of communication, spare batteries, food rations and water. If necessary, the platform should allow transport of the wounded. It is anticipated that the basic form of using the platform will be to support the infantry squad or platoon. The platform will be brought to the area of operations, and during the implementation of support tasks will be controlled by means of a personal control station or by means of a system following the guide. Effective implementation of this type of mission requires from the platform:

- high transport susceptibility (indispensable for not having to accompany the main forces and quickly reach the area of operation);

- quick transition from transport to work position;

- ability to overcome terrain obstacles both when driving at full load and without load;

- in favorable conditions, the ability to follow a guide;

- very high longitudinal and transverse stability, both unloaded and loaded.

Critical for the mission are:

- the ability to overcome ground road ditches and other obstacles with and without load;

- ability to maintain stability with and without load;

- ability to develop low speed also while overcoming obstacles;

- ability to support subunits for a long time without replenishing energy sources.

This places particularly high demands on the chassis together with the drive system and the load space, which should be shaped in such a way that the mass of the load influences the distribution of pressures to the ground and developed tractive forces as well as does not disturb the platform's stability. The task analysis indicated that the chassis should meet a whole range of different requirements, including:

- ensure high stability while driving and working - it is therefore inadvisable to use flexible suspensions;

- provide a large cargo space necessary to assemble the attachments, in particular the manipulator in the transport position;

- provide a relatively long platform length, significantly improving the ability to overcome roadside ditches;

- copy terrain irregularities very well and ensure an even distribution of pressure on the ground in order to develop high traction forces necessary to overcome terrain obstacles and develop towing and pulling forces;

- ensure low unit pressure on the ground (indicated smaller than necessary for detonation of mines), enabling to overcome areas with low carrying capacity;

- provide low rolling resistance - with a long length and limited width, it eliminates the possibility of using a side-turn steering system;

- provide low resistance movements, also on unpaved surfaces;

- reduce vibrations generated by ground unevenness, disrupting the operation of detectors and teleoperation system cameras;

- reduce noise emissions during ride.

In addition, it should have a relatively small width (it should not exceed $1.25 \mathrm{~m}$ ) and low own weight. 
The imposed expectations limit the possibilities of shaping the chassis structure. The problem is aggravated by relatively small allowable sizes and low weight. The theory and design principles developed for standard, heavy vehicles cannot be directly used. This is particularly true in the area of terramechanics (vehicle-terrain interaction), where extrapolation becomes very risky. In this field, knowledge is based on experimental research and the size of systems cooperating with the ground and the magnitude of the pressures. The developed relationships are valid only in the scope of the studied population of solutions and the existing loads. The designed platform differs significantly from them, both in terms of weight, pressures and dimensions - hence, you cannot uncritically reach for recommendations and indicators developed for tanks or other off-road vehicles. In the case of heavy vehicles, the best ability to overcome terrain obstacles (and developing tractive forces) is characterized by tracked vehicles with side torsion, which are normally used by metal tracks, sometimes equipped with rubber overlays. They are characterized by low ground pressure and relatively low rolling resistance. On paved roads, they do not exceed $4-5 \%$ of gravity. The disadvantages of this solution include: very high rolling resistance, low durability (about 6-9 thousand $\mathrm{km}$, i.e. $250-400 \mathrm{~h}$ at speeds of $25 \mathrm{~km} / \mathrm{h}$ ) and high operating costs as well as the generation of relatively high noise. For this reason, in mini machines (weighing up to 6-7 t) and because of significantly lower loads - elastomer tracks are dominant. They are characterized by: significantly longer durability (about 2,500-4,000 hrs. of work), a relatively low price, and are quiet and allow you to move on hardened roads (they do not damage the surface).

The research carried out at the Military University of Technology confirms these advantages. However, they point out (the "Dromader" testbed vehicle that the rolling resistance of elastomer tracks even on load-bearing substrates is 2-3 times higher (reaching 15\% of gravity) than the resistance of rolling heavy steel tracked caterpillar tracks. This results in a much higher engine load and proportionally higher fuel consumption. This is essential for the weight of the drive unit (extended cooling system) and the necessary size of the fuel tank, and consequently its mass. These features are extremely important and disadvantageous for the intended application. In addition, drive road wheels of the protrusions and grooves of the elastomeric tread induce significant vibrations of the entire vehicle - it is advisable to use susceptible elements to suppress the generated vibrations. A serious disadvantage of standard solutions of tracked chassis, with side steering systems, is their high rolling resistance. The resistance reduction requires that the length of the track on the ground does not exceed $80 \%$ of track spacing, and it is a solution commonly used in mini-machines, excavators, bulldozers and other maneuvering machines. However, this results that the machines are relatively short and wide, with low longitudinal stability and high sensitivity to unevenness. For these reasons, this indicator is about $170 \%$ in high-speed vehicles. The price for good longitudinal stability is high resistance to turning. A certain solution to the problem is the division of the track and the use of an articulated steering system. With a relatively large track length on the ground (the sum of the length of 2 tracks), the rolling resistance is only about 2 times higher resistance to driving. Such a system was tested on the testbed vehicle "Dromader". It uses commercial, standard delta elastomer tracks. Tests of undepreciated elastomeric systems have shown that despite the undoubted advantages (availability, reliability, high adhesion), the use of standard solutions leads to an increase in the mass of the structure (mass of a single track exceeds $40 \mathrm{~kg}$ ), generates high rolling resistance (reach $15 \%$ of gravity on smooth hard surfaces) and can generate significant vibrations. The reduction of these defects would require the development of their own design, which would increase the risk of the project. For these reasons, it was assumed to use wheeled chassis. The review of the solutions of drive system used in high mobility vehicles shows that in terms of the ability to overcome obstacles, the most advantageous solution is $8 \mathrm{x} 8$ wheeled drive systems. Wheels are then most often connected in pairs attached to a trolley one. To ensure high maneuverability and terrain copying ability (uniformity of wheel loads on the ground), an articulated steering system and swivel elements connection are used. This solution also allows for the installation of track belts. The high mobility of the platform with such a chassis has been confirmed by computer simulations carried out in MUT.

Designing the chassis, it was necessary to pay attention to the possibility of its significant overloads. This is indicated by the report of months of tests of the combat use of robots carried out by the United States Army. During maneuvers, it was common to overload their bearing structure by up to $100 \%$. The soldiers did not comply with the technical limitations and used them not only for transporting cargo, but also as means of their own transport. In almost two months practically all were seriously damaged due to this. During designing, special attention was also required for lateral stability. A report from these tests indicates that all platforms involved in the test had problems in this area and were knocked over. Most often this occurred during night exercises with the use of night vision devices, which shorten the perspective and distort the assessment of distances and obstacles. It also pointed to common problems with overloading and overheating drive systems, especially in rough terrain, when riding at low speeds. The platforms were equipped with an electric drive and required stopping the engines to cool down. They were also characterized by far too small operational range (in the order of $16 \mathrm{~km}$ ). Power generators were commonly used to supply them. In addition, it was found that platforms developing maximum speeds of $8 \mathrm{~km} / \mathrm{h}$ limit the mobility of sub-units (they limited the speed of movement of soldiers). Therefore, it is advisable to develop speeds of at least $12 \mathrm{~km} / \mathrm{h}$. Two load standards were adopted when creating the logistic platform concept, two elementary loading standards were assumed - a military backpack (height of $70 \mathrm{~cm}$, width of $35 \mathrm{~cm}$, depth of $30 \mathrm{~cm}$, loading mass of $30 \mathrm{~kg}$ ) and an ammunition box (height of $17 \mathrm{~cm}$, width of $35 \mathrm{~cm}$, depth of $50 \mathrm{~cm}$ and mass of $24 \mathrm{~kg}$ ). Moreover, possibilities of transporting the wounded on stretchers (width of $60 \mathrm{~cm}$, length of $220 \mathrm{~cm}$ ) were considered. It was assumed the platform should transport 10 ammunition boxes or 8 backpacks (payload $240 \mathrm{~kg}$ ). The conceptual solution developed for the platform (Fig.1.) allows transport of 3 rucksacks on the front and 5 rucksacks on the rear section and radio stations in an easily accessible place on the side of the front platform part. Backpacks are inserted into the cargo space and hooked (hung) additionally by the ear of a special frame. They can also be hung outside the rack 


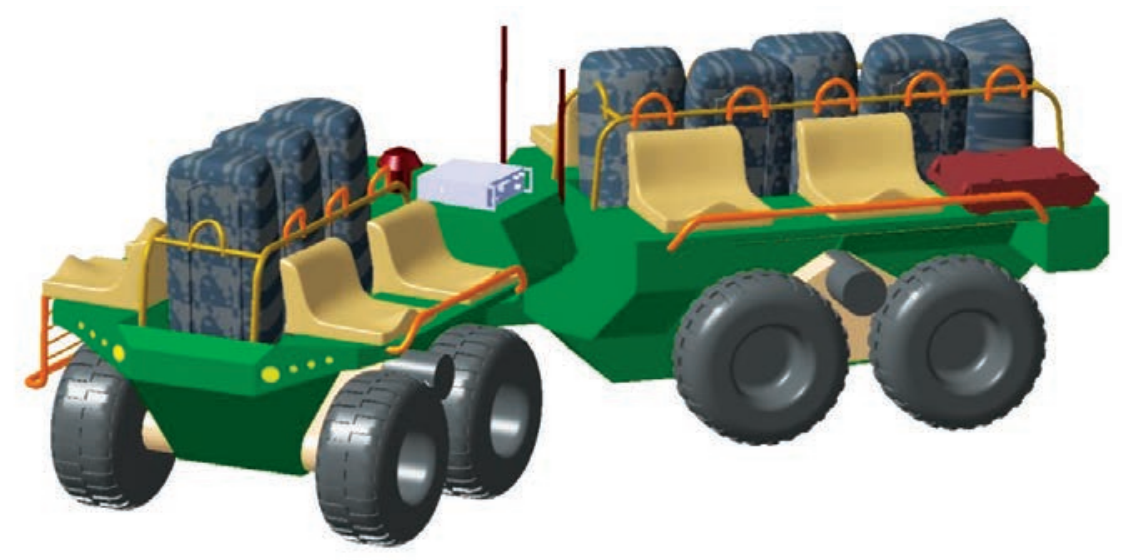

Fig.1. The maximum load on the platform with backpacks

Inside the cargo space (between the sides) there are 10 ammunition boxes in 2 layers ( 4 on the front part and 6 on the rear section) allowing you to load lightweight equipment or backpacks on them. This can cause overloading of the structure by an additional $250 \mathrm{~kg}$. The distribution of the load in this case is beneficial and should not pose a significant problem. Of course, the platform with an additional load will not be able to overcome steep climbs (60\%) and other obstacles due to the limited amount of propulsive force and deterioration of its stability. Optionally, 8 seats can be placed on the sides of the platform, which in favorable conditions (low rolling resistance, low resistance of the slope, small transversal inclinations) enable transport of soldiers - (Fig.2.).

However, it can cause a significant overload of the structure - up to $500 \mathrm{~kg}$. This is a serious structural challenge, causing the necessity of extremely meticulous analysis of the impact of this factor on the accepted mass of the carrier. The dimensions of the platform, and especially its rear section, allow transport of two injured on a stretcher - Figure 3 - placed on the sides. It does not reduce the load space, however it requires the use of additional telescopic brackets and slightly reduces the stability (especially when the load is asymmetric).

Another option for transporting injured people is to assemble the central frame of the rear section and place the stretcher in the middle - Fig.4. It does not require the use of telescopic brackets, it improves transverse stability, but it significantly reduces the load space.

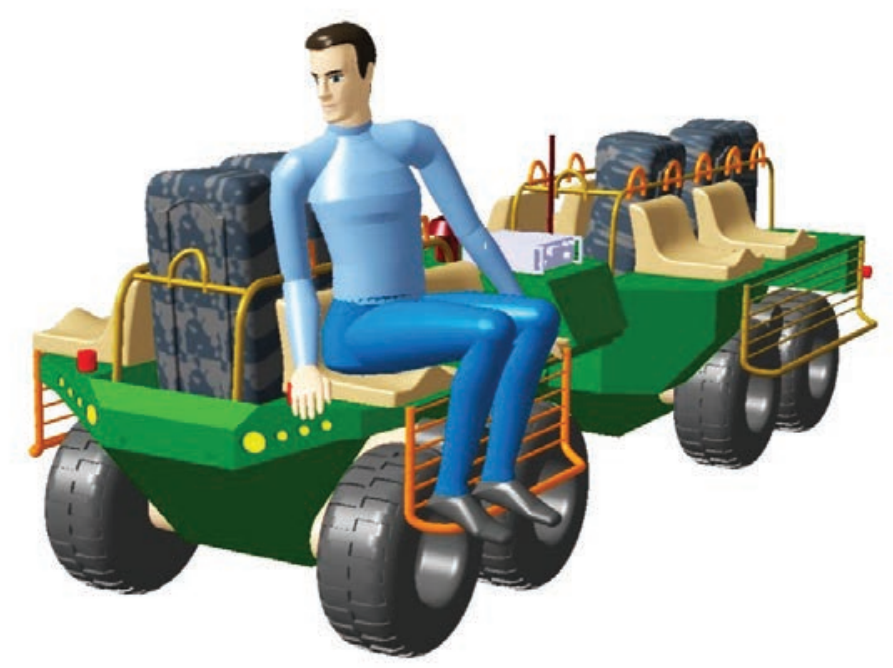

Fig.2. Under favorable conditions, the platform can carry up to 8 soldiers the legs of soldiers must be protected with special folding shields 


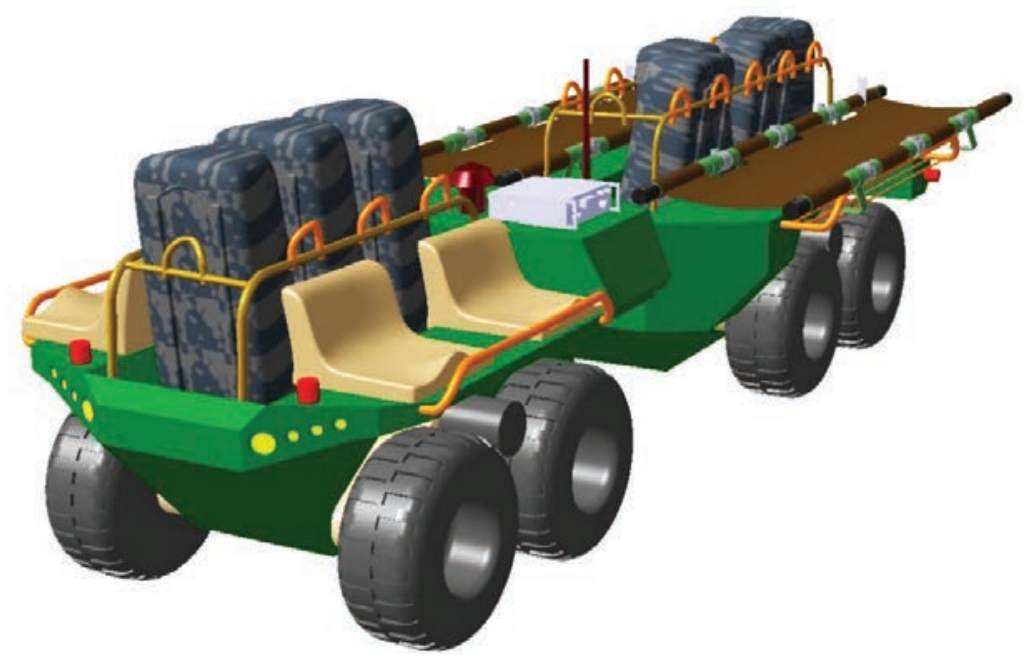

Fig. 3. The platform allows transport on the sides of 2 stretchers, but this requires the use of additional telescopic brackets

The developed platform concept ensures high longitudinal and lateral stability, also in the turn (Fig.5) - due to the appropriate configuration of the load space and even load distribution.

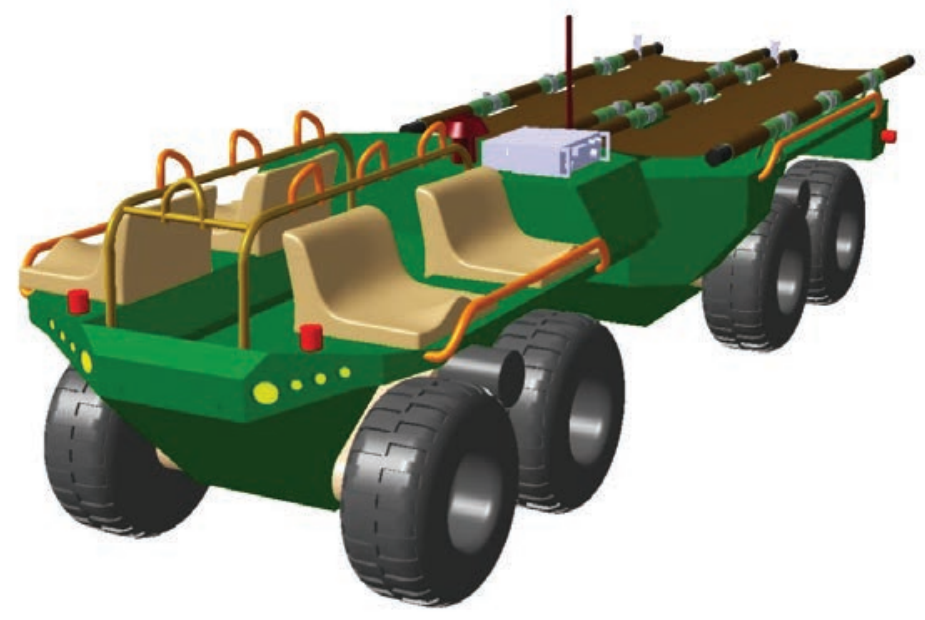

Fig. 4. Transport of the stretcher after folding the central frame of the rear section

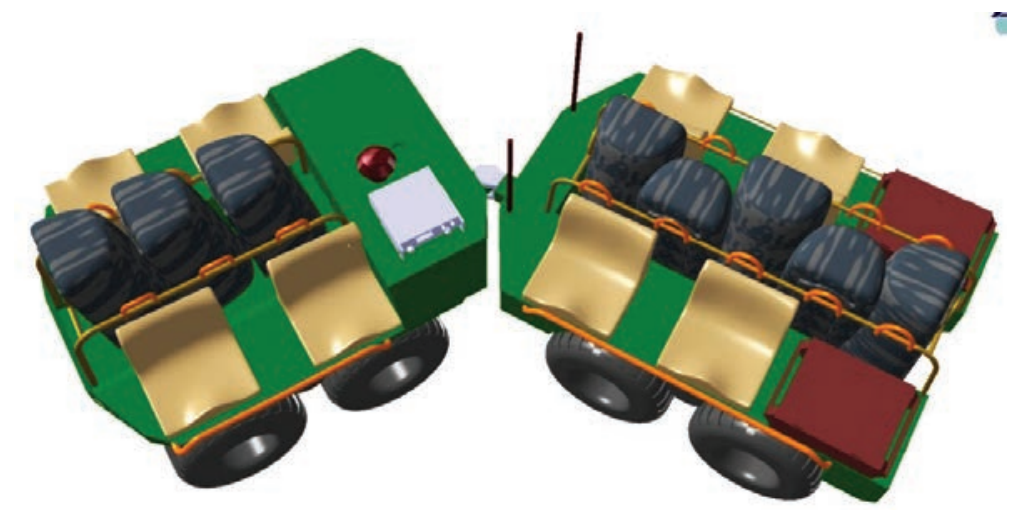

Fig.5. Load distribution ensures high platform stability also in the turn

\section{Conclusions}

The developed conception will be the basis to building mobility demonstratives, which will allow for verifying the assumptions and for final shaping of the logistic support robots, which could - in the nearest future - become a part of equipment of the Polish military forces. The logistic platform concept has been shaped in terms of mobility and 
work possibilities in such a way as to obtain the right traction force, maximum speed, transverse static and dynamic stability, distribution and mass values (distribution of component components), ability to overcome terrain obstacles, overall platform width, tire selection, approach and departure angles and ground clearance. The analyzes necessary for this purpose were carried out in an analytical and simulation way. During shaping its constructions, following conditions were presumed:

- maximum speed - $12-15 \mathrm{~km} / \mathrm{h}$;

- climb slope - 60\% (ability to drive);

- cross slope - $30 \%$ (ability to drive);

- payload - $250 \mathrm{~kg}$;

- weight - $550 \mathrm{~kg}$;

- turning radius (curb-to-curb)- 2,5 m;

- width - 1,25 m;

- worktime - $10 \mathrm{~h}$;

- the ability to cross roadside ditches with a hill slope of $50 \%$, a bottom width of $0.4 \mathrm{~m}$ and a depth

of $0.7 \mathrm{~m}$;

- possibility of observing the area from a height of $3.5 \mathrm{~m}$;

- width 1,2 m;

- deck height $0,75 \mathrm{~m}$;

- height to the antenna frame $1,8 \mathrm{~m}$.

\section{Acknowledgements}

This work was conducted within the framework of the project "Platforma średnia (klasa $800 \mathrm{~kg}$ )" - grant no. DOBRBIO4/083/13431/2013. The authors are thankful for the Polish "National Centre for Research and Development".

\section{References}

1. Studium wykonalności projektu Programu Strategicznego na rzecz bezpieczeństwa i obronności państwa pt.: Rodzina bezzałogowych platform lądowych (BPL) do zastosowań w systemach bezpieczeństwa I obronności Państwa. WAT, Warsaw 2012.

2. Dąbrowska A., Konopka S., Przybysz M., Rubiec A.: Ability to negotiate terrain obstacles by lightweight six-wheeled unmanned ground vehicles. 10th International Conference ITELMS 2015, Panevėžys, Lithuania 2015.

3. Dąbrowska A., Jaskółowski M., Krogul P., Spadło K.: Mobility evaluation of a lightweight four-wheel unmanned ground vehicle with articulated steering system. 10th International Conference ITELMS 2015, Panevėzys, Lithuania 2015.

4. Dąbrowska A., Krogul P., Rubiec A.: Co - simulation study into properties of wheeled robot hydropneumatic suspension system. 3th European Conference of the International Society for Terrain Vehicle Systems, Rome 2015

5. Jaskółowski M. B., Konopka S., Łopatka M.J.: Research of dynamic stability of articulated UGV, Proceedings of 11th International Conference on Intelligent Technologies in Logistics and Mechatronics Systems ITELMS’2016, Medimond Publishing Company, Panevėžys, Lithuania 2016.

6. Massey K: Squad Mission Equipment Transport (SMET). Lessons Learned for Industry. NDIA Ground Robotic Capability Conference 2016.

7. Patrick Lin, Ph.D. George Bekey, Ph.D. Keith Abney, M.A.: Autonomous Military Robotics: Risk, Ethics, and Design. Department of the Navy, Office of Naval Research, under awards \# N00014-07-1-1152 and N00014-08-1-1209 December 20, 2008.

8. Cedric Richardson: JIEDDO’s Robotics Programs. Military Robitics Summit. Washington 29 August 2012 DC,USA, 2012.

9. Aleksandr Blokhin, Alla Koshurina, Maxim Krasheninnikov, Roman Dorofeev: The Analytical Review of the Condition of Heavy Class Military and Dual Purpose Unmanned Ground Vehicle. MATEC Web of Conferences 26, 04002 ( 2015), EDP Sciences, 2015. 